\title{
Vitamin D mitigates the adverse effects of obesity on breast cancer in mice
}

\author{
Srilatha Swami', Aruna V Krishnan², Jasmaine Williams2,3, Abhishek Aggarwal2, \\ Megan A Albertelli4, Ronald L Horst5, Brian J Feldman²,3,6,7 and David Feldman,7 \\ 'Department of Medicine-Endocrinology, Stanford University School of Medicine, Stanford, CA, USA \\ 2Department of Pediatrics-Endocrinology, Stanford University School of Medicine, Stanford, CA, USA \\ ${ }^{3}$ Cancer Biology Program, Stanford University School of Medicine, Stanford, CA, USA \\ ${ }^{4}$ Department of Comparative Medicine, Stanford University School of Medicine, Stanford, CA, USA \\ ${ }^{5}$ Heartland Assays Inc, Ames, IA, USA \\ ${ }^{6}$ Institute for Stem Cell Biology and Regenerative Medicine, Stanford University School of Medicine, \\ Stanford, CA, USA \\ ${ }^{7}$ Stanford Cancer Institute, Stanford University School of Medicine, Stanford, CA, USA
}

Correspondence should be addressed to D Feldman or B Feldman Email

dfeldman@stanford.edu or feldman@stanford.edu

\begin{abstract}
Obesity is an established risk factor for postmenopausal breast cancer (BCa), insulin resistance, and vitamin $D$ deficiency, and all contribute to increased synthesis of mammary estrogens, the drivers of estrogen receptor-positive (ER+) BCa growth. As both dietary vitamin $D$ and calcitriol treatments inhibit breast estrogen synthesis and signaling, we hypothesized that vitamin $D$ would be especially beneficial in mitigating the adverse effects of obesity on ER+BCa. To assess whether obesity exerted adverse effects on BCa growth and whether vitamin D compounds could reduce these unfavorable effects, we employed a diet-induced obesity (DIO) model in ovariectomized C57BL/6 mice. Breast tumor cells originally from syngeneic $M m t v-W n t 1$ transgenic mice were then implanted into the mammary fat pads of lean and obese mice. DIO accelerated the initiation and progression of the mammary tumors. Treatments with either calcitriol or dietary vitamin $D$ reduced the adverse effects of obesity causing a delay in tumor appearance and inhibiting continued tumor growth. Beneficial actions of treatments with vitamin D or calcitriol on $\mathrm{BCa}$ and surrounding adipose tissue included repressed Esr1, aromatase, and Cox2 expression; decreased tumor-derived estrogen and $\mathrm{PGE}_{2}$; reduced expression of leptin receptors; and increased adiponectin receptors. We demonstrate that vitamin $D$ treatments decreased insulin resistance, reduced leptin, and increased adiponectin signaling and also regulated the LKB1/AMPK pathway contributing to an overall decrease in local estrogen synthesis in the obese mice. We conclude that calcitriol and dietary vitamin D, acting by multiple interrelated pathways, mitigate obesity-enhanced BCa growth in a postmenopausal setting.
\end{abstract}

\section{Introduction}

The incidence of obesity in the general population is rising and becoming widespread worldwide. In the USA, overweight $\left(\mathrm{BMI}=25-29.9 \mathrm{~kg} / \mathrm{m}^{2}\right)$ and obese
(BMI $\geq 30 \mathrm{~kg} / \mathrm{m}^{2}$ ) individuals together constitute almost two-thirds of the population (Wang et al. 2011). Obesity is a risk factor for breast cancer (BCa), especially 
postmenopausal estrogen receptor $\alpha$-positive (ESR1), and is associated with increased incidence as well as poor prognosis and response to treatment (Gilbert \& Slingerland 2013, Iyengar et al. 2015). The hypothesized mechanisms for the adverse effects of obesity on $\mathrm{BCa}$ include increased inflammation in obese adipose tissue with high cytokine and adipokine levels that create a chronic inflammatory microenvironment favoring tumor cell motility, invasion, and epithelial-mesenchymal transition (EMT) (Gilbert \& Slingerland 2013). Obesity is also frequently associated with systemic insulin resistance and elevated proinflammatory mediators and growth factors, leading to the interplay of local and systemic effects including elevated levels of leptin, circulating insulin, and IGF1 (Gilbert \& Slingerland 2013). Leptin, a protein synthesized and secreted by adipose cells, circulates at levels proportional to adiposity and has many actions that stimulate breast cancer growth (Grossmann et al. 2010, Strong et al. 2015).

In the breast microenvironment, there is local estrogen synthesis by adipose stroma and tumor cells, which drive BCa growth (Howe et al. 2013, Simpson $\&$ Brown 2013a). This local estrogen production is especially significant in postmenopausal women whose estrogen synthesis from dormant ovaries is greatly diminished, resulting in low circulating levels of estrogens. Additionally, obesity and elevated leptin cause dysregulated metabolism and inhibition of the tumor suppressor AMPK that can constrain cell proliferation by multiple mechanisms including the LKB1/AMPK pathway (Simpson \& Brown 2013a). It has been shown that AMPK negatively regulates the actions of CREB-dependent aromatase, the enzyme that catalyzes the synthesis of estrogens in breast adipose tissue, via phosphorylation of CRTC2, a transcription factor required for the activation of the aromatase promoter PII in BCa cells (Luo et al. 2010, Simpson \& Brown 2013a,b, Wang et al. 2015). Finally, there is evidence linking obesity and associated insulin resistance (Hursting \& Berger 2010, Mitri \& Pittas 2014 , Allott \& Hursting 2015) with changes in the breast adipose stromal compartment that result in increased inflammation (Berstein et al. 2007, Maccio et al. 2009, Brown \& Simpson 2010, Howe et al. 2013), leading to the development of an adverse adipokine milieu (Simpson \& Brown 2013a,b) and culminating in increased synthesis of estrogen, which drives postmenopausal BCa progression (Wang et al. 2015).

Others and we have shown that supplementation with dietary vitamin $\mathrm{D}$ or treatment with its active hormonal form calcitriol $\left[1,25(\mathrm{OH})_{2} \mathrm{D}_{3}\right]$ exhibits multiple actions to inhibit $\mathrm{BCa}$ growth as demonstrated in cultured $\mathrm{BCa}$ cells and in lean mouse models of BCa (Deeb et al. 2007, Welsh 2012, Feldman et al. 2014, Shui \& Giovannucci 2014, Rossdeutscher et al. 2015, So \& Suh 2015). These vitamin $\mathrm{D}$ actions include the transcriptional repression of aromatase (Cyp19 (Cyp19a1)) (Krishnan et al. 2010, Swami et al. 2011), inhibition of Esr1 expression (Swami et al. 2000, 2013), and suppression of cyclo-oxygenase-2 (Cox2) expression (Moreno et al. 2005), leading to the reduction in the synthesis of pro-inflammatory mediators such as $\mathrm{PGE}_{2}$ that are major stimulators of aromatase transcription in BCa (Brown \& Simpson 2010, Simpson \& Brown 2013a). Dietary vitamin D acts equivalently to calcitriol (Swami et al. 2012) and exerts anti-inflammatory effects (Krishnan \& Feldman 2011) and reduces insulin resistance by improving insulin secretion and signaling (Calle et al. 2008). As estrogens are the major driver of $E R+$ BCa growth (McDaniel et al. 2013), these multiple vitamin $\mathrm{D}$ and calcitriol actions provide a rationale for using vitamin D supplementation to reduce BCa risk and improve outcomes.

Although many studies mentioned above have examined the benefits of vitamin $\mathrm{D}$ in cancer using a variety of models, previous reports have not examined whether vitamin $\mathrm{D}$ or calcitriol has the capacity to mitigate the negative effects of obesity on breast cancer. In this study, we have examined the ability of calcitriol and dietary vitamin D supplementation to alter the growth of mouse mammary tumor virus Mmtv-Wnt1 in an ovariectomized (OVX), diet-induced obesity (DIO) model and compared the effects in obese mice to lean mice. Our novel findings indicate that DIO promotes $\mathrm{BCa}$ initiation and growth and that calcitriol and dietary vitamin D supplementation reduces the adverse effects of obesity on BCa development and progression. We show for the first time that vitamin D compounds mitigate the adverse effects of obesity by multiple mechanisms both systemically and directly on the tumor cells and the surrounding adipose tissue leading to improvement in insulin resistance and the suppression of local/ breast estrogen synthesis by inhibiting prostaglandin production and altering the adipokine expression profile and signaling. In addition, we discovered that vitamin D compounds enhance pAMPK pathways that suppress local estrogen synthesis in the breast microenvironment that are enhanced by obesity. Our results suggest that calcitriol or dietary vitamin D supplementation would be a particularly beneficial adjunct in the treatment of $(\mathrm{ER}+) \mathrm{BCa}$ in obese, postmenopausal patients where these adverse pathways are substantially enhanced.

Published by Bioscientifica Ltd 


\section{Materials and methods}

\section{Materials}

Calcitriol was from Santa Cruz Biotechnology Inc. Rodent diets were from Research Diets Inc. (New Brunswick, NJ, USA). Tissue culture media, supplements, and fetal bovine serum (FBS) were from GIBCO BRL (Grand Island, NY, USA) and Mediatech Inc. (Herndon, VA, USA).

\section{Methods}

Mice All animal procedures were performed in compliance with the guidelines approved by Stanford University Administrative Panels on Laboratory Animal Care (APLAC). Female 6-week old, OVX C57BL6/NCr mice were from Charles River Laboratories. Mice were housed in the Research Animal Facility, Stanford University School of Medicine, in a designated pathogen-free area.

Animal studies and treatments The OVX mice were randomized to receive either a standard AIN76 diet (STD: $11 \%$ fat, $24 \%$ protein, and 64\% carbohydrate-derived calories) or an AIN76 high-fat diet (HFD: 60\% fat, 20\% protein, and $20 \%$ carbohydrate-derived calories). The source of fat in the diets was from lard. Body weights were assessed weekly to monitor weight gain. After 10 weeks, mammary tumors were established in all mice by orthotopic implantation of Mmtv-Wnt1 tumor cells into their mammary fat pads. The tumor cell preparations were made from spontaneously developing mammary tumors in Mmtv-Wnt1 transgenic mice on a C57BL6/NCr background (a gift from Dr Stephen Hursting, University of North Carolina, Chapel Hill, NC, USA) that are Esr+ and growth inhibited by tamoxifen (Nunez et al. 2008, Yue et al. 2005). Tumor cells $(\sim 150,000)$ suspended in a small volume of a 1:1 mixture of culture medium (RPMI $+10 \%$ fetal bovine serum) and matrigel were inoculated into the fourth mammary fat pad of each mouse. The procedure was performed under APLAC-approved conditions with carprofen $(5 \mathrm{mg} / \mathrm{kg}$ ) for analgesia. The mice were then randomly assigned to the various treatment groups, and diets were continued for the following 6 weeks (Fig. 1). Both STD and HFD contained 530 IU of vitamin $\mathrm{D}_{3} / \mathrm{kg}$. The vitamin D-supplemented (VD) STD and HFD contained $5300 \mathrm{IU}$ of vitamin $\mathrm{D}_{3} / \mathrm{kg}$. Calcitriol (Cal), diluted in sterile PBS was administered at a dose of $25 \mathrm{ng}$ given by i.p. injections three times a week (Swami et al. 2011). Control mice (STD and HFD) received i.p. injections of $0.1 \%$ ethanol in sterile PBS.

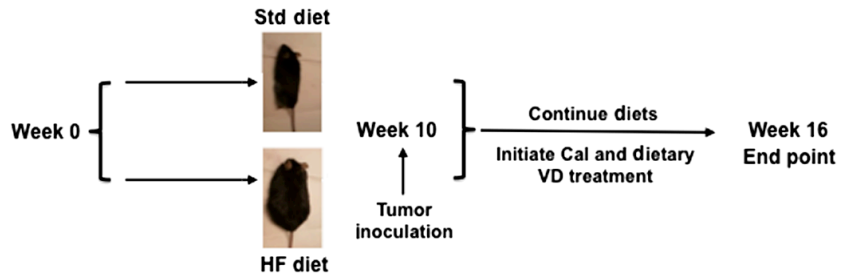

Figure 1

Schematic representation of experimental design. OVX female C57BL6/NCr mice were randomized to receive either a standard diet AIN76 (STD: 11\% fat, $24 \%$ protein, and $64 \%$ carbohydrate-derived calories) or a AIN76 high-fat diet (HFD: $60 \%$ fat, $20 \%$ protein, and $20 \%$ carbohydrate-derived calories). Body weights were monitored weekly to assess weight gain. The HFD-fed mice developed substantial obesity after 10 weeks at which time mammary tumors were established in both lean and obese mice by orthotopic implantation of Mmtv-Wnt1 tumor cells into their mammary fat pads. The mice were continued on the experimental diets and treated with vehicle (Con), calcitriol (Cal), or dietary vitamin D (VD) supplementation for the following 6 weeks. At the end of 6 weeks, animals were killed and serum, tumor tissue, and surrounding mammary fat were collected for further analyses. A full colour version of this figure is available at http://dx.doi.org/10.1530/ERC-15-0557.

Tumor sizes were measured weekly and tumor volumes were calculated from two tumor diameter measurements with a digital caliper using the formula: tumor volume $=\left(\right.$ length $\times$ width $\left.^{2}\right) / 2$. At the end of the study, $14 \mathrm{~h}$ after the final calcitriol injections, mice were killed according to APLAC guidelines using $\mathrm{CO}_{2}$. Blood was collected by cardiac puncture, serum separated, and frozen. Tumors and surrounding adipose tissue were harvested and snap frozen in liquid nitrogen for subsequent analysis.

Measurement of serum calcium and vitamin $D$ metabolites Serum calcium was measured with an ELISA kit (Cayman Chemical Company). Serum 25-hydroxyvitamin $\mathrm{D}(25(\mathrm{OH}) \mathrm{D})$ and $1,25(\mathrm{OH})_{2} \mathrm{D}$ levels were measured at Heartland Assays (Ames, IA, USA) by methods previously described (Hollis et al. 1993, 1996). The assays did not distinguish between vitamin $\mathrm{D}_{2}$ or $\mathrm{D}_{3}$ metabolites.

Evaluation of insulin resistance Insulin resistance was estimated by the homoeostasis model assessment of insulin resistance (HOMA-IR) (Matthews et al. 1985) using the formula [fasting serum insulin $(\mu \mathrm{U} / \mathrm{mL}) \times$ fasting blood glucose $(\mathrm{mmol} / \mathrm{L})] / 22.5$. Pancreatic $\beta$-cell function was assessed by the homeostasis model assessment of $\beta$-cell function (HOMA- $\beta$ ) using the formula $[20 \times$ fasting serum insulin concentration $(\mu \mathrm{U} / \mathrm{mL})] /[$ fasting blood glucose (mmol/L) -3.5] (Matthews et al. 1985).

Published by Bioscientifica Ltd. 
Quantitative reverse transcriptase-PCR Total RNA was isolated from tumor and mammary adipose tissue using Trizol (Invitrogen, Carlsbad, CA, USA) (Moreno et al. 2005). RNA (5 $\mu$ g) were subjected to reverse transcription using the SuperScript III first strand synthesis kit (Invitrogen) (Krishnan et al. 2010). Relative changes in mRNA levels were assessed using gene-specific primers (Table 1) by the comparative $\mathrm{C}_{\mathrm{T}}\left(\Delta \Delta \mathrm{C}_{\mathrm{T}}\right)$ method and were normalized to that of TATA box-binding protein $(T b p)$ or glyceraldehyde-3-phosphate dehydrogenase (Gapdh) mRNA levels.

Measurement of hormones and adipokines One week before the experimental end point, an APLACapproved saphenous vein blood draw procedure was employed to obtain fasting blood samples from a subset of all mice after a 6-h fast. Fasting blood glucose levels were measured using a glucometer (Free Style, Abbott Diabetes Care Inc, Alameda, CA, USA). Fasting serum samples were assayed for insulin (EMD Millipore Corporation) and triglycerides (Cayman Chemical Company) using ELISA. Protein extracts from tumor and the surrounding mammary fat were prepared in Tris-EDTA buffer containing high salt (Zhao et al. 1999) and protein concentration determined by the method of Bradford (1976). ELISA kits were used to measure estradiol $\left(\mathrm{E}_{2}\right)$ (Cayman Chemical Company), estrone $\left(\mathrm{E}_{1}\right)$ (ALPCO Immuno Assays, Salem, NH, USA), and $\mathrm{PGE}_{2}$ (Cayman Chemical Company). Serum leptin and adiponectin were measured in mammary fat extracts and, at the end of the study, serum samples by ELISA (EMD Millipore Corporation).

Table 1 Mouse primer sequences.

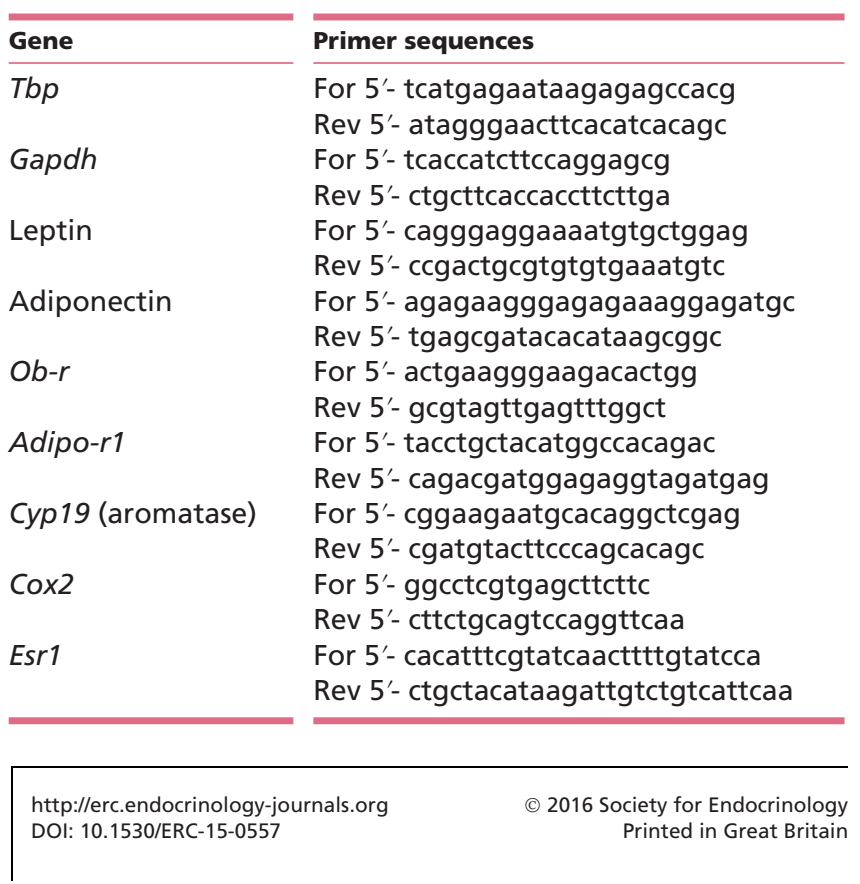

LKB1 promoter activity in MCF-7 breast cancer cells MCF-7 human BCa cells were routinely cultured in DMEM:F12 medium supplemented with 10\% FBS and maintained at $37^{\circ} \mathrm{C}$ and $5 \% \mathrm{CO}_{2}$ in a humidified chamber. An $\sim 3 \mathrm{~Kb}$ LKB1 promoter (a kind gift from Dr E Simpson and K Brown, Monash University, Australia) inserted into a pGL3-basic reporter vector was transiently transfected into MCF-7 cells using Lipofectamine 2000 reagent (Life Technologies/Invitrogen) according to the manufacturer's instructions. Following transfections, the cells were treated with vehicle $(0.1 \%$ ethanol) or varying concentrations $(0.1-10 \mathrm{nM})$ of calcitriol for $24 \mathrm{~h}$. In a separate set of experiments, the $L K B 1$ promoter construct was co-transfected with human vitamin $\mathrm{D}$ receptor (VDR) expression plasmid into MCF-7 cells and treated with $10 \mathrm{nM}$ calcitriol as described above. Luciferase activity was measured using the Luciferase assay kit (Promega) according to the manufacturer's instructions.

pAMPK in tumor and MCF-7 breast cancer cells MCF-7 cell cultures grown to $75 \%$ confluency were treated with vehicle $(0.1 \%$ ethanol), calcitriol $(10 \mathrm{nM})$, leptin $(100 \mathrm{ng} / \mathrm{mL})$, or adiponectin $(500 \mathrm{ng} / \mathrm{mL})$ for $24 \mathrm{~h}$. Protein extracts from tumor and surrounding mammary fat were processed simultaneously. Extracts from tumors or cells were used to measure total AMPK using the DuoSet IC ELISA (R\&D Systems). Phosphorylation of AMPK was assayed using the PathScan Phospho-AMPKa (Thr172) Sandwich ELISA (Cell Signaling Technology), a solid-phase ELISA that detects endogenous levels of AMPKa when phosphorylated at Thr172.

Statistical analysis Statistical analyses were performed using the GraphPad Prism 5 software (GraphPad Software, San Diego, CA, USA). Data were evaluated by ANOVA with Scheffe's F test as the post hoc analysis.

\section{Results}

\section{Effects of diets and treatments on body weight, serum vitamin D metabolites, and serum calcium}

Ingestion of the HFD over 10 weeks caused significant obesity compared with mice fed the STD (Fig. 2A). Tumor cell inoculation and VD and Cal treatments began at week 10. Calcitriol treatment did not alter the body weights in the lean mice $(S T D+C a l)$. However, a decrease in the body weight in the obese HFD+Cal group was observed

Published by Bioscientifica Ltd. 


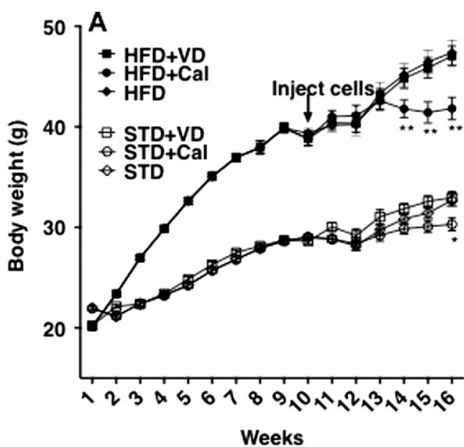

$E$
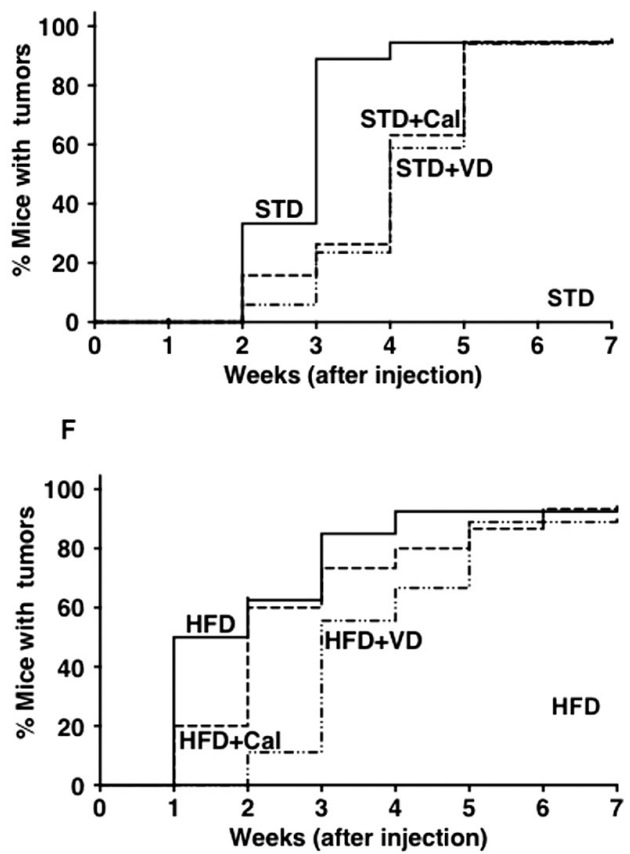

G

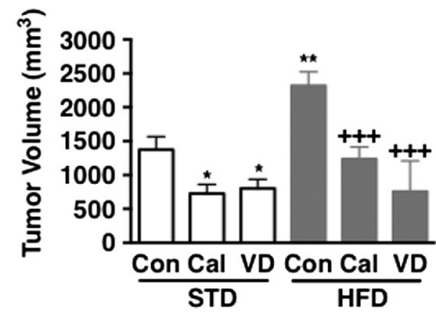

Figure 2

Effect of diets and treatments on body weight, tumor appearance and growth, and serum calcium and vitamin $D$ metabolites. The mice fed either a STD (lean mice) or HFD diet (obese mice) bearing $M m t v-W n t 1$ orthografts were treated with either calcitriol (Cal) or dietary vitamin D supplementation (VD) as described in the Methods section. (A) Body weight changes with the different diets and treatments. (B, C, D) Serum 25 hydroxyvitamin $D[25(\mathrm{OH}) \mathrm{D}], 1,25$ dihydroxyvitamin $\mathrm{D}[1,25(\mathrm{OH}) 2 \mathrm{D}]$ and calcium measurements at endpoint. $(E, F)$ Appearance of tumors in the different experimental groups monitored from the time of tumor implantation until endpoint represented as Kaplan-Meier plots. (G) Tumor volume measured at endpoint. Values represent mean \pm s.E. of 10-12 mice in each group. $* P<0.05 ; * * P<0.01 ; * * * P<0.001$ when compared to STD-CON and $+P<0.05 ;++P<0.01 ;{ }^{+++} P<0.001$ when compared to HFD-CON. starting at week 13 and continuing through the end of the experiment, a sign of calcitriol toxicity causing hypercalcemia (Fig. 2B). There were no significant changes in body weights compared with controls in the lean and obese mice receiving VD.

We measured the concentrations of $25(\mathrm{OH}) \mathrm{D}$ and $1,25(\mathrm{OH})_{2} \mathrm{D}$ in the serum from all mice. Although mice fed a STD +VD or HFD+VD had significant elevations in $25(\mathrm{OH}) \mathrm{D}$, the circulating form of vitamin $\mathrm{D}$ (Fig. $2 \mathrm{~B}$ ), no changes were detected in the levels of 25(OH)D with just HFD alone. This was contrary to the findings in the literature where obesity is associated with vitamin D deficiency. This unexpected finding could be attributed to the presence of lard in the diet. Lard is good source of vitamin $\mathrm{D}$, and we suspect that this contributed to the observed levels of $25(\mathrm{OH}) \mathrm{D}$ in the mice fed HFD obviating the relationship between vitamin D deficiency and obesity. As expected, calcitriol treatment caused significant decreases in serum 25(OH)D levels in both lean and obese mice from increased catabolism of $25(\mathrm{OH})$ D due to induction of the degradative enzyme CYP24A1. Interestingly, vitamin D-supplemented diets caused increases in serum $1,25(\mathrm{OH})_{2} \mathrm{D}$ levels (Fig. $2 \mathrm{C}$ ), a phenomenon we have previously described in other mouse $\mathrm{BCa}$ models following the administration of a vitamin D-supplemented diet. We attributed this effect to increased local $1,25(\mathrm{OH})_{2} \mathrm{D}$ synthesis and secretion by the tumors in response to elevated serum $25(\mathrm{OH}) \mathrm{D}$ substrate, as increase in serum $1,25(\mathrm{OH})_{2} \mathrm{D}$ was not seen in supplemented mice without tumors (Swami et al. 2012). Serum calcium levels remained unchanged except for modest but statistically significant elevations in serum calcium levels in the obese mice treated 
with calcitriol (Fig. 2D). The mild hypercalcemia indicated that the calcitriol dose was a maximal dose that could be administered with limited toxicity.

\section{Effects of DIO and treatments on tumor appearance and growth}

Within 1 week of tumor cell inoculation, palpable tumors were evident in $50 \%$ of the obese mice (HFD), whereas 50\% tumor appearance in the lean mice (STD) was detected 2 weeks later (Fig. 2E). The administration of calcitriol or VD to obese mice (HFD) caused a delay in tumor appearance with $50 \%$ of the obese mice showing palpable tumors by 1 and 2 weeks after tumor cell inoculation, respectively, compared with week 1 for the non-treated obese mice (Fig. 2F). Calcitriol or VD administered to the lean mice (STD) delayed tumor appearance with $50 \%$ of the treated lean mice exhibiting palpable tumors by week 4 compared with week 3 for the mice fed the STD alone. Comparing the time until the appearance of palpable tumors in $50 \%$ of mice, there was a 3-week delay between the obese mice receiving no treatments and the lean mice receiving calcitriol or VD (Fig. 2E and F). As the interval from inoculation to termination of the experiment was 6 weeks, the 3 -week difference in tumor appearance was quite substantial $(P<0.01)$.

We next compared the end point tumor volumes. As shown in Fig. 2G, the tumor volume in the obese mice was significantly greater than that in the lean mice ( $74 \%$ increase), indicating an increased rate of tumor growth in the obese mice. In the lean mice, calcitriol and VD treatments resulted in decreased mean tumor volumes (by $\sim 46 \%$ and $\sim 40 \%$ respectively) compared with STD alone. However, calcitriol and VD treatment of the obese mice caused even more significant decreases in the mean tumor volumes compared with untreated mice on the HFD ( $\sim 7 \%$ decrease in HFD + Cal and $\sim 67 \%$ decrease in HFD + VD compared with HFD). These results demonstrate that both vitamin $\mathrm{D}$ treatments inhibited tumor growth and that treatment with vitamin $\mathrm{D}$ was sufficient to mitigate the adverse effect of obesity on tumor growth in these mice.

\section{Effects of DIO and treatments on aromatase expression, estrogen synthesis, and $\mathrm{PGE}_{2}$ production}

In order to understand the mechanisms by which vitamin D treatment mitigates the effects of obesity, we next examined the expression of aromatase, in both the tumors and the surrounding mammary fat. Very significant elevations in aromatase mRNA expression were seen both in the mammary fat (Fig. 3A) and tumor tissue (Fig. 3B) in the obese mice. Calcitriol and VD decreased aromatase mRNA expression in both lean and obese mice, with the decreases being more pronounced in the obese mice. Measurement of estradiol $\left(\mathrm{E}_{2}\right)$ concentration in extracts of tumors and surrounding mammary fat also revealed decreases similar to those seen in aromatase mRNA. Considerable elevations in $\mathrm{E}_{2}$ levels in tumor and mammary fat were seen in the obese mice, which were substantially reduced following treatments with calcitriol and VD (Fig. 3C and D). Estrone $\left(\mathrm{E}_{1}\right)$ concentrations in the mammary fat extracts were also elevated in the obese mice and the levels were reduced by the treatments (Fig. 3E and F). Although there was a trend toward increased $E_{1}$ in the tumors of the obese mice, these changes were not statistically significant.

We also examined the changes in the expression of Cox 2 and $\mathrm{PGE}_{2}$ concentrations in breast tumors. A considerable increase in Cox 2 mRNA was evident in the tumors from obese mice (Fig. 3G). Calcitriol and VD treatments significantly decreased Cox 2 mRNA in both lean and obese mice, with the decreases being more pronounced in the obese mice. The obese mice showed a modest increase in tumor $\mathrm{PGE}_{2}$ levels. Administration of calcitriol to both lean and obese mice significantly decreased tumor $\mathrm{PGE}_{2}$ levels, while the decrease due to dietary VD was only evident in the obese mice (Fig. 3H).

Obesity substantially elevated the expression of Esr1, the mediator of estrogen's mitogenic signaling (Fig. 3I). Both calcitriol and VD caused large reductions in tumor Esr1 mRNA expression in both lean and obese mice, but again, the decreases were more pronounced in the obese mice, which had four-fold higher levels of tumor Esr1 mRNA compared with the lean mice.

\section{Effects of DIO and treatments on systemic measures of insulin resistance}

The weight gain seen in the obese mice was associated with expected changes in metabolic parameters measured in fasting serum samples. As shown in Table 2, there were statistically significant increases in fasting serum insulin and triglycerides in obese mice compared with lean mice. Fasting glucose levels also showed an increasing trend, which, however, did not achieve statistical significance. HOMA-IR was statistically significantly elevated in the obese mice, indicating an increased insulin resistance explained by the higher insulin concentration required

Published by Bioscientifica Ltd. 

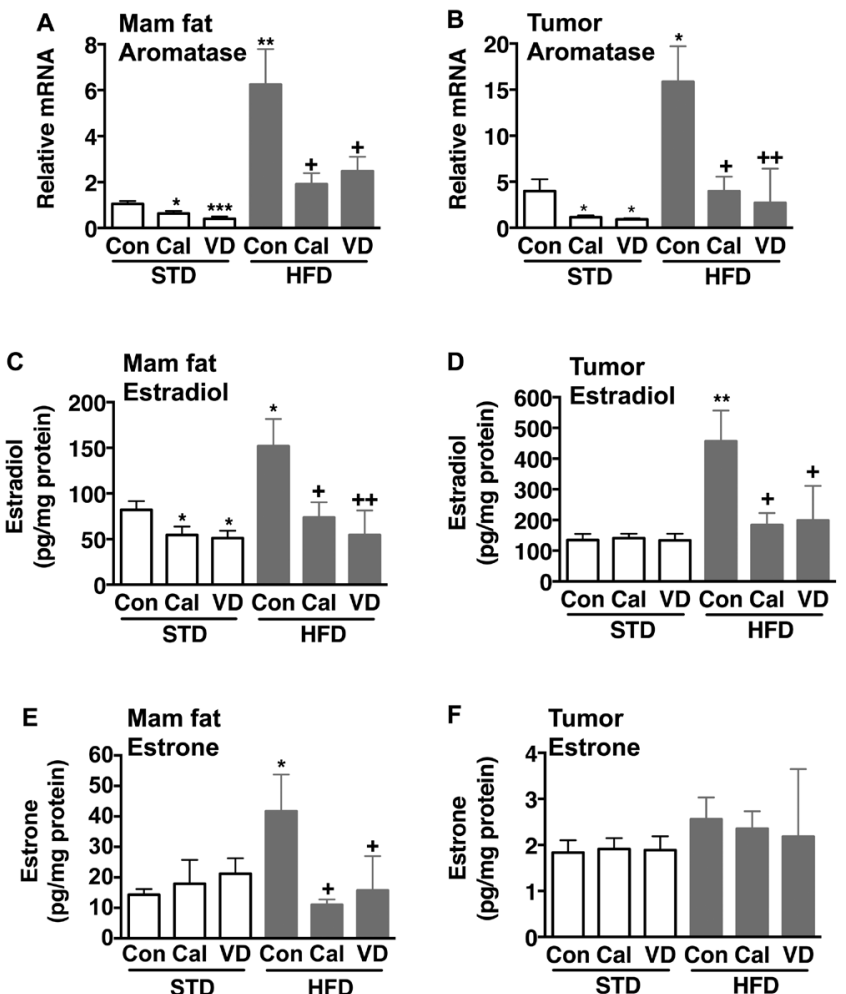

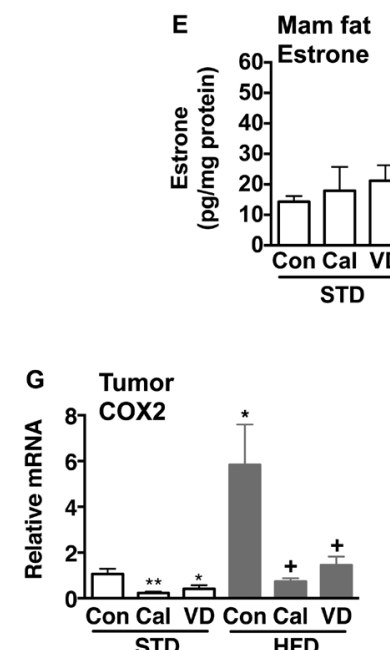

STD

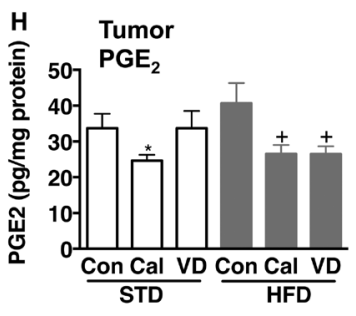

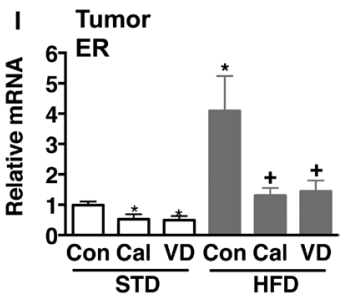

Figure 3

Estrogen synthesis and signaling after treatment with calcitriol or dietary vitamin $\mathrm{D}$ supplementation. Mmtv-Wnt1 tumors established in C57BL/6 OVX female mice following STD (lean mice) or HFD (obese mice) were treated with either calcitriol (Cal) or dietary vitamin $\mathrm{D}$ supplementation (VD). Tumors and surrounding mammary fat were harvested for isolation of total RNA and protein extracts as described in the Methods section. (A) Mammary fat aromatase mRNA, (B) tumor aromatase mRNA, (C) mammary fat estradiol, (D) tumor estradiol, (E) mammary fat estrone, (F) tumor estrone, (G) tumor Cox2 mRNA, (H) tumor $\mathrm{PGE}_{2}$, and (I) tumor Esr1 mRNA. Relative changes in mRNA levels were assessed using gene-specific primers by the comparative $C_{T}$ $\left(\Delta \Delta C_{T}\right)$ method and were normalized to that of TATA box-binding protein (TBP) and glyceraldehyde-3-phosphate dehydrogenase (GAPDH) mRNA levels. Values represent mean \pm S.E.M. of $10-12$ mice in each group. $* P<0.05, * * P<0.01, * * * P<0.001$ when compared with STD-CON and $+P<0.05,++P<0.01,{ }^{+++} P<0.001$ when compared with HFD-CON. to maintain a similar level of glucose. Calcitriol improved most of these metabolic parameters; however, the improvement was more pronounced in the obese mice. For example, while calcitriol treatment significantly reduced fasting insulin concentrations in both lean and obese mice, the decreases in glucose and triglyceride levels and HOMA-IR due to calcitriol were statistically significant only in the obese mice. VD similarly showed decreasing trends in insulin levels and HOMA-IR with the decrease in HOMA-IR in the obese mice reaching statistical significance. There were no statistically significant changes in HOMA- $\beta$ (Table 2). Overall, calcitriol seemed more effective than vitamin $\mathrm{D}$ supplementation. We hypothesize that while local conversion to $1,25(\mathrm{OH})_{2} \mathrm{D}_{3}$ plays an important role for the effects of VD on the tumors, this might be less evident in the multiple sites that regulate the insulin resistance and homeostasis.

\section{Effects of DIO and treatments on circulating and local adipokines}

As obesity-induced changes in adipokines have been linked to increased BCa risk and worse prognosis, serum leptin and adiponectin concentrations were measured in all mice at the time of killing (Fig. 4A and B). The obese mice showed an approximately three-fold increase in the mean serum leptin, a reflection of their increased obesity. Calcitriol and vitamin D significantly reduced serum leptin levels in both lean and obese mice showing systemic as well as local beneficial effects. No significant change was observed in serum adiponectin concentrations in the obese compared with lean mice. However, calcitriol treatment caused modest but statistically significant increases in serum adiponectin in both lean and obese mice, whereas vitamin $\mathrm{D}$ produced a very modest but also 
statistically significant increase in serum adiponectin only in the lean mice.

Next, we examined the expression of leptin and adiponectin in the mammary fat surrounding the tumors to determine whether the systemic effects of obesity were also occurring locally in the breast adipose tissue. As shown in Fig. 4C, a substantial increase in leptin mRNA expression was seen in the mammary fat of obese mice when compared with the lean mice. Administration of calcitriol and vitamin D caused significant decreases in leptin mRNA expression in both lean and obese mice. Modest decreases in adiponectin mRNA (Fig. 4D) expression in the mammary fat were seen in obese mice compared with lean mice, which were not statistically significant. Administration of calcitriol and VD significantly increased mammary fat adiponectin mRNA expression in the obese mice, while the increase in lean mice did not achieve significance. ELISA measurements for leptin and adiponectin protein showed that the inhibitory changes in mammary fat leptin mirrored the leptin mRNA changes (Fig. 4E). Mammary fat adiponectin protein was reduced in obese mice but changes after vitamin D treatments were not significant (Fig. 4F). We also determined leptin receptor $(\mathrm{Ob}-\mathrm{r})$ and adiponectin receptor (Adipo-r1 and Adipo-r2) mRNA expression in the tumors. The obese mice showed a significant increase in tumor Ob-r mRNA (Fig. 4G) and a modest increase in Adipo-r1 mRNA compared with the lean mice (Fig. 4H). Adipor2 mRNA expression in the tumors was negligible. Both calcitriol and VD significantly decreased $O b-r$ mRNA in the obese mice (Fig. 4G), while further increasing Adipo-r1 mRNA levels in the tumors from obese mice (Fig. $4 \mathrm{H}$ ). The effects of calcitriol and VD were, however, minimal in the lean mice. Overall, these changes indicate a particularly important role for vitamin D treatments to inhibit the elevated leptin signaling and stimulate adiponectin signaling in the tumors of the obese mice.

\section{Effects of DIO and calcitriol treatment on AMPK activation}

The LKB1/AMPK pathway has been shown to play an important role in the downstream effects of prostaglandins and adipokines in $\mathrm{BCa}$ associated with obesity (Simpson \& Brown 2013a, b, Wang et al. 2015). As $M m t v$-Wnt1 cells do not grow well in culture, we used cultured human MCF-7 BCa cells to address the role of calcitriol on the regulation of LKB1 and pAMPK. A dose-dependent increase in the basal LKB1 luciferase promoter activity was seen (Fig. 5A) with calcitriol treatment. Co-transfection of $h V D R$ expression plasmid elicited a 1.5 -fold increase in the basal promoter activity and this was further enhanced with calcitriol treatment (Fig. 5B), suggesting a direct action of calcitriol via the $V D R$ on the $L K B 1$ promoter. We next examined the effects of calcitriol on the activation of AMPK, a direct target for the actions of LKB1. MCF-7 cells were treated with calcitriol, leptin, or adiponectin for $24 \mathrm{~h}$. No significant changes were observed in the levels of total AMPK; however, both adiponectin and calcitriol treatments significantly increased the levels of pAMPK (Fig. 5C and D). Leptin did not alter the levels of AMPK or pAMPK at the dose tested. We next investigated whether calcitriol regulated pAMPK levels in the tumors and surrounding mammary fat in both lean and obese mice. No changes were observed in the levels of total AMPK in either the tumor (Fig. 5E) or the surrounding mammary fat (Fig. 5G). Basal pAMPK levels were slightly lower in both the tumor and surrounding mammary fat in the obese mice compared with the lean mice and a significant

Table 2 Fasting Serum Measurements in lean (STD) and obese (HFD) fed mice.

\begin{tabular}{|c|c|c|c|c|c|}
\hline Groups & $\begin{array}{l}\text { Glucose } \\
\text { (mg/dL) }\end{array}$ & $\begin{array}{l}\text { Triglycerides } \\
\text { (mg/dL) }\end{array}$ & $\begin{array}{l}\text { Insulin } \\
(\mu \mathrm{IU} / \mathrm{mL})\end{array}$ & HOMA-IR & HOMA-beta \\
\hline \multicolumn{6}{|l|}{ STD } \\
\hline STD & $124.6 \pm 18.0$ & $66.0 \pm 9.1$ & $37.4 \pm 3.4$ & $11.6 \pm 2.2$ & $210 \pm 48$ \\
\hline STD + Cal & $136.8 \pm 21.8$ & $60.9 \pm 6.2$ & $23.4 \pm 3.8^{a}$ & $9.2 \pm 1.3$ & $356 \pm 243$ \\
\hline STD + VD & $130.5 \pm 14.4$ & $65.3 \pm 7.8$ & $32.5 \pm 6.7$ & $7.7 \pm 0.7$ & $248 \pm 44$ \\
\hline \multicolumn{6}{|l|}{ HFD } \\
\hline HFD & $155.0 \pm 15.5$ & $89.2 \pm 4.9^{a}$ & $67.7 \pm 10^{a}$ & $27.0 \pm 5.6^{a a}$ & $221 \pm 35$ \\
\hline HFD + Cal & $114.2 \pm 7.9^{b}$ & $74.1 \pm 4.1^{b}$ & $39.5 \pm 4.5^{b}$ & $11.1 \pm 1.5^{b b}$ & $309 \pm 66$ \\
\hline HFD + VD & $130.2 \pm 8.9$ & $75.9 \pm 1.2^{b}$ & $52.7 \pm 7.0$ & $13.2 \pm 1.2^{b}$ & $333 \pm 20$ \\
\hline
\end{tabular}

STD, standard diet; HFD, high-fat diet; Cal, calcitriol; VD, dietary vitamin D supplementation (5300 IU/kg diet). Values represent mean S.E.M. of 5-8 determinations. a $P<0.05$, aa $P<0.01$ compared with STD; ${ }^{\mathrm{b}} P<0.05$, bb $P<0.01$ as compared with HFD. 
A

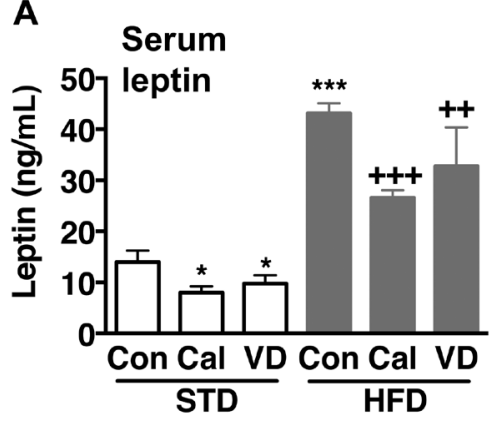

C Mam fat
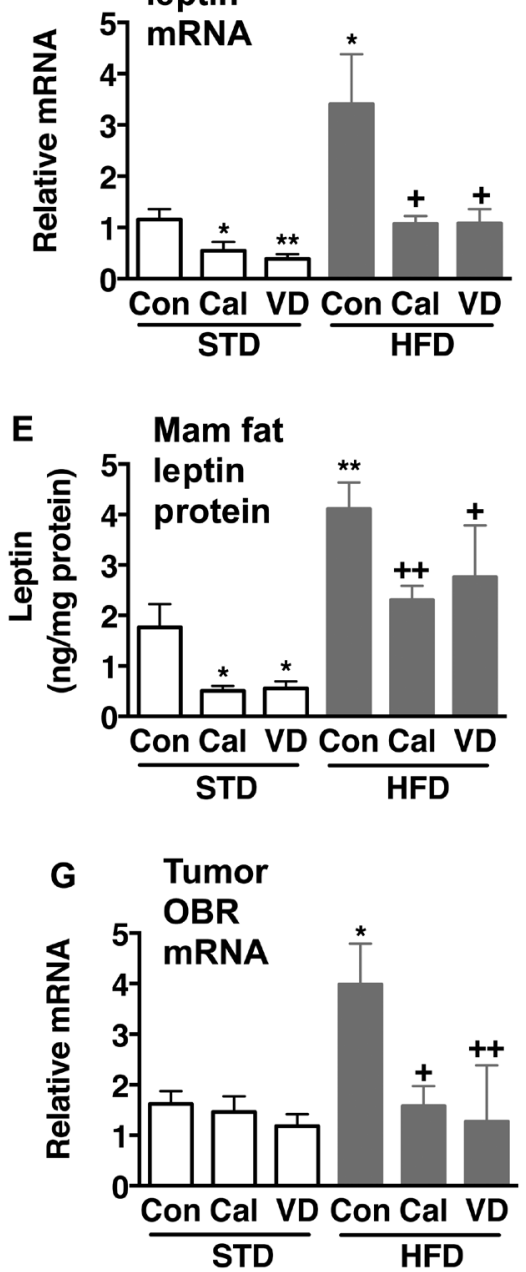
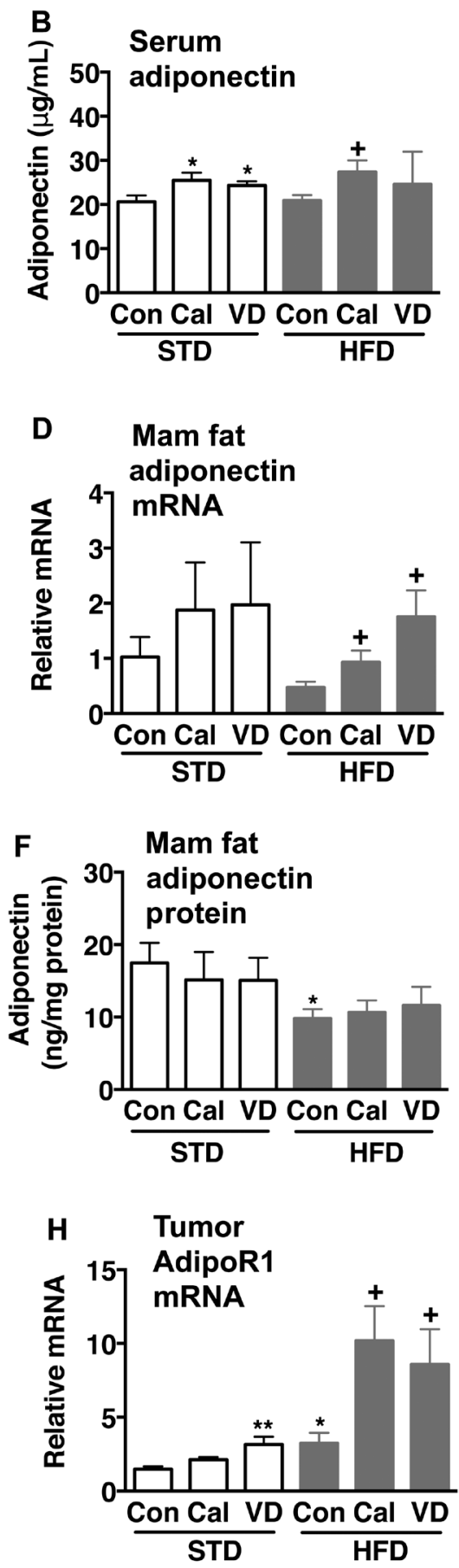

Figure 4

Effect of treatment with calcitriol or dietary vitamin $\mathrm{D}$ supplementation on the adipokine profile. Mmtv-Wnt1 tumors established in C57BL6/NCr mice following STD (lean mice) or HFD (obese mice) were treated with either calcitriol (Cal) or dietary vitamin D supplementation (VD). Serum was collected at end point and measured for (A) leptin and (B) adiponectin. Tumors and surrounding mammary fat were collected after terminal killing. Total RNA was isolated from mammary fat and mRNA levels of (C) leptin and (D) adiponectin were determined by qPCR as described in the Methods section. Protein extracts of mammary fat were used for the measurement of (E) leptin and (F) adiponectin using ELISA as described in the Methods section. Total RNA extracts isolated from the tumors were processed for the expression of (G) leptin receptor Ob-r and (H) adiponectin receptor Adipo-r1. Relative changes in mRNA levels were assessed using gene-specific primers by the comparative $C_{T}$ $\left(\Delta \Delta C_{T}\right)$ method and were normalized to that of TATA box-binding protein (TBP) and glyceraldehyde-3-phosphate dehydrogenase (GAPDH) mRNA levels. Values represent mean \pm S.E.M. of 10-12 mice in each group. $* P<0.05, * * P<0.01, * * * P<0.001$ when compared with STD-CON and $+P<0.05,{ }^{++} P<0.01,{ }^{+++} P<0.001$ when compared with HFD-CON. increase in pAMPK levels were seen in both the lean and obese mice with calcitriol treatment (Fig. $5 \mathrm{~F}$ and $\mathrm{H}$ ).

\section{Discussion}

Previous studies from our laboratory using non-obese models have identified several important vitamin D actions that inhibit the progression of postmenopausal ESR1
BCa (Krishnan et al. 2012, Feldman et al. 2014). Because obesity is associated with both vitamin D deficiency (Liel et al. 1988, Boonchaya-anant et al. 2014) and increased BCa risk (Ahn et al. 2007, Gilbert \& Slingerland 2013, Iyengar et al. 2015), we hypothesized that vitamin D supplementation might be an especially useful adjunctive therapy in obese BCa patients. Our current study examined the adverse endocrine, metabolic, and inflammatory 


\section{LKB1 promoter}

A

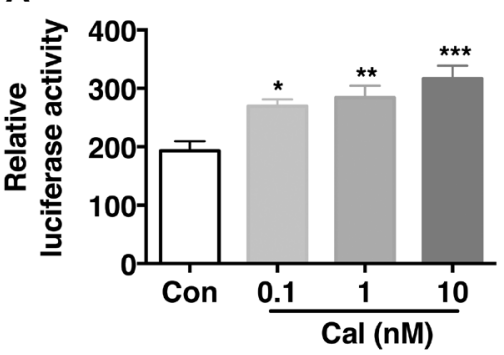

B

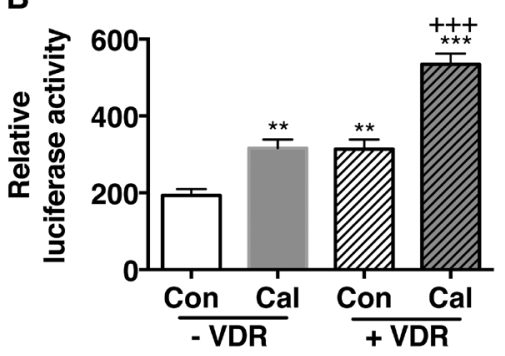

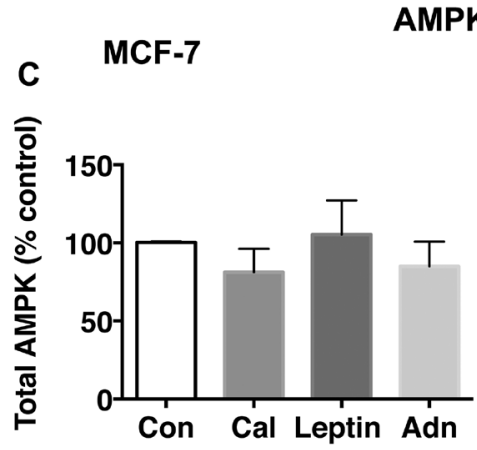

Tumor

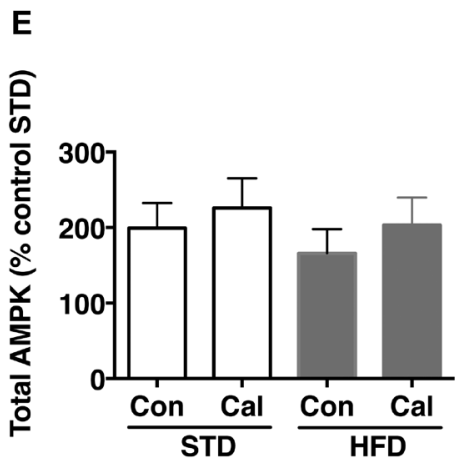

Mammary fat

G

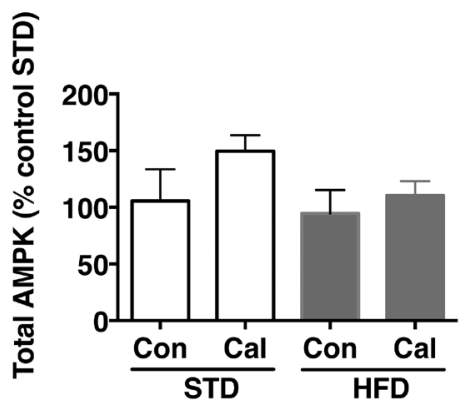

F

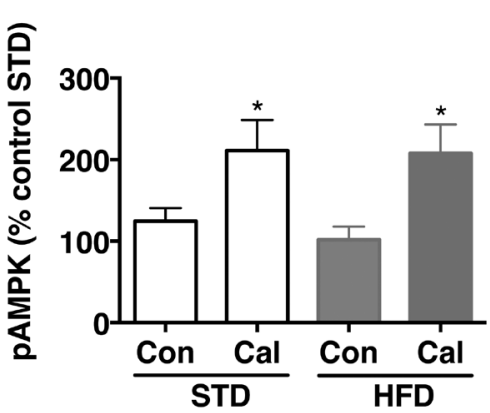

H

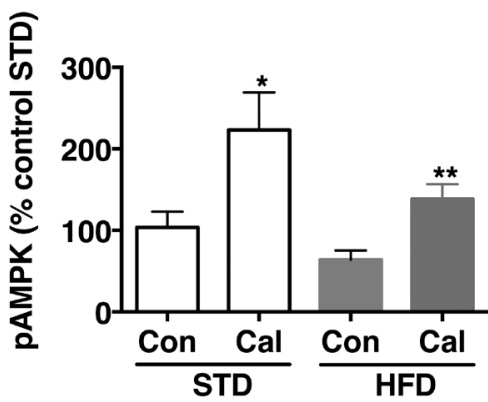

Figure 5

Effect of calcitriol or dietary vitamin D supplementation on AMPK phosphorylation at Thr172 and regulation of $L K B 1$ promoter activity. MCF-7 human BCa cells cultured in DMEM:F12 medium were grown to $\sim 75 \%$ confluency and a $3 \mathrm{~Kb}$ LKB1 luciferase reporter construct was transiently transfected as described in the Methods section. Cells were treated with vehicle ( $0.1 \%$ ethanol: Con) or varying doses of calcitriol (Cal) as indicated. At the end of $24 \mathrm{~h}$, cells were scraped into passive lysis buffer and processed for the measurement of luciferase. (A) Dose response to calcitriol and (B) co-transfection of $h V D R$ and LKB1 reporter activity. Values are represented as relative luciferase activity. Values represent mean \pm S.E.M. of four experiments assayed in duplicate. ${ }^{*} P<0.05$, when compared with Con. MCF-7 human BCa cells cultured in DMEM:F12 medium grown to $\sim 75 \%$ confluency and then treated with vehicle $(0.1 \%$ ethanol: Con), calcitriol (Cal: $10 \mathrm{nM})$, leptin $(100 \mathrm{ng} / \mathrm{mL})$ or adiponectin (Adn: $500 \mathrm{ng} / \mathrm{mL}$ ). Leptin and adiponectin treatments represent experimental controls. At the end of $24 \mathrm{~h}$, cells were scraped into Tris-EDTA buffer and processed for the measurement of (C) total AMPK and (D) PAMPK as described in the Methods section. Values represent mean \pm S.E.M. of four measurements assayed in duplicate. ${ }^{*} P<0.05$, when compared with Con. Tumors ( $E$ and $F$ ) and mammary fat ( $\mathrm{G}$ and $\mathrm{H})$ were also harvested from lean (STD) and obese (HFD) mice treated with calcitriol (Cal) and processed for measurements of total AMPK and PAMPK respectively. Values represent mean \pm S.E.M. of six to eight mice in each group. $* P<0.05, * * P<0.01, * * * P<0.001$ when compared with STD-CON and $+P<0.05,++P<0.01$, ${ }^{++} P<0.001$ when compared with HFD-CON. environment of BCa exacerbated by diet-induced obesity compared with lean mice and the improvement in multiple BCa risk factors as a result of supplementation with VD or treatment with calcitriol.
As reported previously (Nunez et al. 2008), we observed that tumors appeared earlier and attained larger volumes in the obese mice, showing that obesity accelerated initial mammary tumor growth as well as progression. Our new 


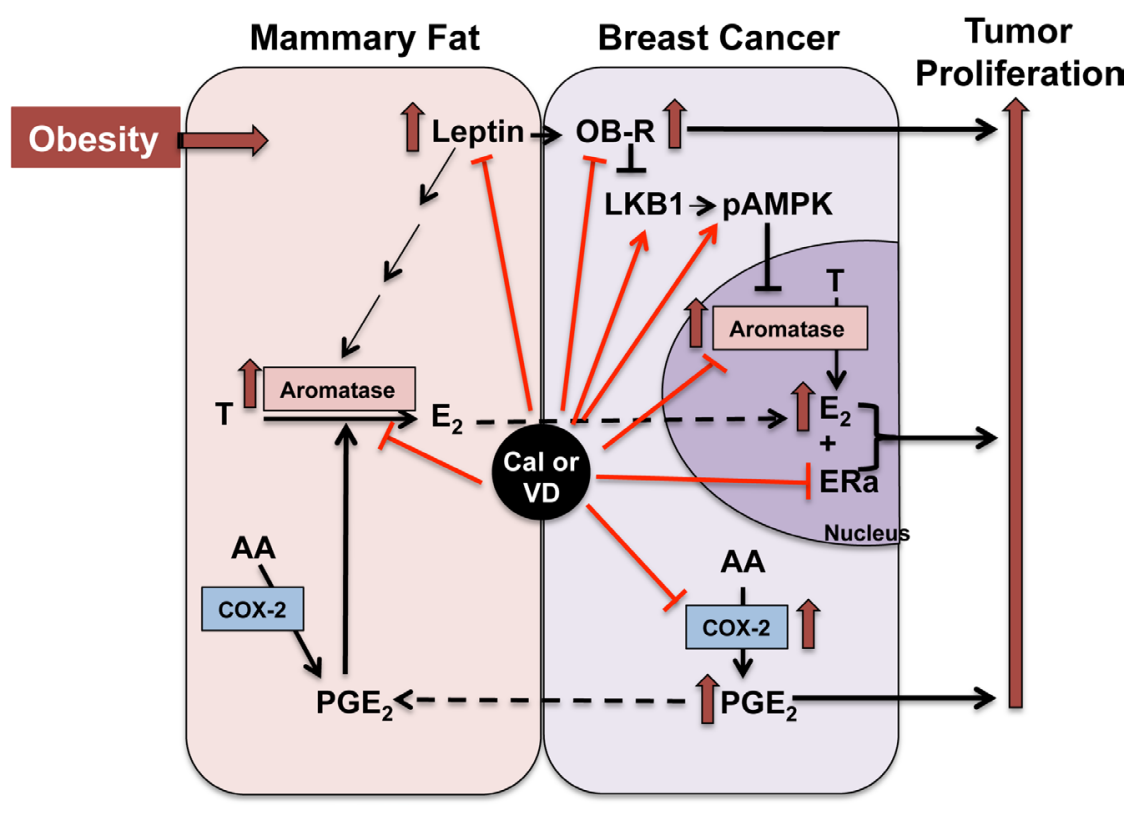

Figure 6

Schematic representation of adipokine and estrogen signaling in diet-induced obesity (DIO) and effects of calcitriol (Cal) or vitamin D (VD) treatment on

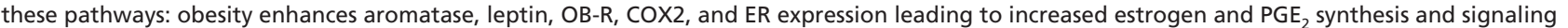
stimulating tumor proliferation. Adiponectin, the most abundant adipokine secreted by the adipose tissue, has insulin-sensitizing effects, and by increasing the expression and activity of the upstream kinase LKB1, it causes the phosphorylation and activation of AMPK (pAMPK). pAMPK prevents nuclear translocation of CRTC2 and activation of the pll promoter of aromatase, the major promoter driving expression of aromatase in BCa. Leptin, however, inhibits insulin signaling, causes the development of insulin resistance, and has the reverse effects on the pAMPK pathway: decrease in LKB1 expression, inactivation of AMPK, enhanced nuclear translocation of CRTC2, and its binding to aromatase pll, resulting in increased aromatase transcription. Thick pointed arrows (brick colour) indicate changes induced by obesity that stimulate BCa. The central blocking arrows (red) indicate some of the major actions mediated by calcitriol or dietary vitamin D supplements that mitigate the adverse effects of obesity. A full colour version of this figure is available at http://dx.doi.org/10.1530/ERC-15-0557.

findings reveal that the beneficial effects of calcitriol and VD are particularly effective at mitigating the adverse factors for BCa growth that are enhanced in obesity. In particular, we discovered that vitamin D and calcitriol, acting on both the tumor and the breast adipose stroma, reduced the obesity-enhanced pathways including elevated estrogen and prostaglandin synthesis, up-regulated Esr1 and Cox2 expression, and the adverse changes in the adipokine profile and adipokine receptor expression patterns associated with obesity. Vitamin D actions to increase pAMPK, in both the tumor and surrounding mammary fat, and regulate LKB1 expression in MCF7 BCa cells, adds additional novel pathways by which vitamin $\mathrm{D}$ retards the rate of tumor growth in the obese mice. Our findings are summarized in the model shown in Fig. 6. Vitamin D and calcitriol treatment, acting systemically, also improved overall insulin resistance in the obese mice.

Local estrogen synthesis in the breast microenvironment is a critical factor increasing the risk of developing breast cancer and driving its growth in postmenopausal women (Bulun et al. 1993). We now show that calcitriol or vitamin $\mathrm{D}$ treatments are beneficial in mitigating the adverse effects of obesity on estrogen synthesis and signaling that are exacerbated in obesity. Our data demonstrate that $\mathrm{BCa}$ in obese mice expressed elevated levels of Esr1 and that the local estrogen synthesis was increased in both the tumor microenvironment as well as the surrounding adipose stroma in the obese mice. The increase in Esr1 and local estrogen synthesis in the obese mice likely contributes to the acceleration in tumor appearance and the augmented tumor growth seen in the obese mice. The vitamin D compounds reduced local estrogen synthesis in the obese mice via suppression of aromatase expression in the breast adipose tissue. Vitamin D treatments also inhibited the elevated expression of Cox2, resulting in decreased prostaglandin synthesis, which we observed in both calcitriol- and VD-treated obese mice. These actions contribute to the inhibition of aromatase and reduced local estrogen synthesis, as $\mathrm{PGE}_{2}$ produced by the mammary tumors is the main stimulator of aromatase promoter pII in the surrounding adipose stroma (Simpson \& Brown 2013a). Others and we have reported (Simboli-Campbell et al. 1997, Swami et al. 2000, 2013) that vitamin D and calcitriol also down-regulate Esr1

Published by Bioscientifica Ltd 
expression in BCa cells and tumors of lean mice. Here, we showed that obese mice have very elevated Esr1 expression and vitamin D treatments substantially inhibited Esr1 expression, thereby interfering with estrogen signaling. The well-established benefit of treating human ER+ BCa with aromatase inhibitors or ER blocking drugs (McDaniel et al. 2013) suggests that these benefits of vitamin $D$ and calcitriol in mice may play a role in human $\mathrm{BCa}$.

Obesity and insulin resistance are associated with changes in the breast adipose-stromal compartment, which result in increased inflammation and the development of an unfavorable adipokine expression profile of increased leptin and decreased adiponectin (Brown et al. 2010, Simpson \& Brown 2013a). Vitamin D treatments reduced the elevated levels of leptin mRNA and protein in both the serum and the breast adipose stroma. Additionally, vitamin D compounds significantly reduced the elevated $O b-r$ mRNA levels while increasing Adipo-r1 mRNA levels in the mammary tumors of obese mice. Although these effects are also found in the lean mice, the changes are more prominent in the obese mice where the leptin levels are much higher than in the lean mice. Overall, our findings indicate that calcitriol and dietary VD mitigate the adverse changes in the adipokine expression pattern seen in the obese mice. These changes also contribute to the increased activation of AMPK and downstream repression of aromatase promoter $\mathrm{pII}$ in the breast adipose tissue.

The regulatory effects of adiponectin and leptin on AMPK, a master regulator of energy homeostasis, contribute to the association between obesity and BCa (Brown et al. 2010, Wang et al. 2015). Adiponectin, the most abundant adipokine secreted by the adipose tissue, has insulin-sensitizing effects (Ouchi et al. 2011), and by increasing the expression and activity of the downstream kinase LKB1, it causes the phosphorylation and activation of AMPK (Brown et al. 2009). In the presence of pAMPK, CRTCs are phosphorylated and translocate to the nucleus to bind CREB-target genes such as aromatase that is thereby inhibited leading to reduced transcription (Simpson et al. 2002). Leptin however inhibits insulin signaling, activating insulin resistance (Grossmann et al. 2010) and has the reverse effects on the pAMPK pathway resulting in increased aromatase transcription (Brown et al. 2009). Thus, the altered adipokine milieu associated with obesity and insulin resistance provides a critical link between obesity and postmenopausal $\mathrm{BCa}$ in which local production of estrogens in the breast adipose tissue is a major driving force for BCa growth. We demonstrate that calcitriol directly stimulates expression of an LKB1-luc construct transfected into MCF-7 BCa cells, an effect enhanced by co-transfection of $V D R$, indicating a direct effect on the $L K B 1$ promoter. Calcitriol and vitamin $\mathrm{D}$ also enhance activation of AMPK to PAMPK, in both the tumor and mammary fat. These actions add additional pathways by which vitamin $\mathrm{D}$ inhibits aromatase expression and mitigates obesity-enhanced adverse effects on BCa (Fig. 6).

In summary, obesity accelerated the progression of Mmtv-Wnt1 mammary tumors in recipient OVX mice. Treatment with calcitriol or VD reduced the adverse effects of obesity on tumor development and growth. Vitamin D or calcitriol showed diverse actions in both the tumor and the adipose stroma to mitigate the adverse effects of obesity including inhibition of aromatase, Cox 2 and Esr 1 expression resulting in diminished estrogen and $\mathrm{PGE}_{2}$ synthesis, improved insulin resistance, diminished unfavorable profile of adipokine expression by reducing leptin and leptin receptor expression and increasing adiponectin receptor expression, increasing $L K B 1$ promoter activity, and increased tumor suppressor pAMPK levels, all contributing to repressed aromatase and limited local estrogen synthesis in the tumor and surrounding breast adipose tissue (Fig. 6). We conclude that calcitriol or VD supplementation exerts multiple beneficial effects specifically relevant to ER+ BCa enhanced by obesity, as these treatments, acting through several interrelated local and systemic mechanisms, cause a significant inhibition of the synthesis of and signaling by local estrogens, which drive the growth of $\mathrm{BCa}$ in the postmenopausal setting. We speculate that these changes, found in OVX lean and obese mice, are also relevant to postmenopausal women. Vitamin D supplementation could be an especially useful adjunctive measure in obese women with $\mathrm{BCa}$ and suggest that a randomized controlled trial to test this hypothesis is warranted.

\section{Declaration of interest}

R L Horst has an ownership interest in Heartlands Assays LLC. The other authors declare that there is no conflict of interest that could be perceived as prejudicing the impartiality of the research reported.

\section{Funding}

This work was supported by California Breast Cancer Research Program Grants 17OB-0071 (DF) and 19IB-0103 (BJF), American Institute of Cancer Research Grant 208633 (DF), and National Institutes of Health T32 CA09302 grant (JW).

\section{Author contribution}

D Feldman, B J Feldman, S Swami, and A V Krishnan conceived and designed the study. S Swami, A V Krishnan, J Williams, M Albertelli, and R L Horst developed the methodology. S Swami, A V Krishnan, J Williams,

Published by Bioscientifica Ltd 
R L Horst, and A Aggarwal participated in acquisition of data. D Feldman, B J Feldman, S Swami, A V Krishnan, and J Williams participated in the analysis and interpretation of data. S Swami, A V Krishnan, D Feldman, B J Feldman, J Williams, R L Horst, A Aggarwal, and M Albertelli participated in the writing, review, and revision of the manuscript. D Feldman, B J Feldman, M Albertelli, and R L Horst provided administrative, technical, and material support. D Feldman and B J Feldman supervised the study.

\section{Acknowledgments}

We thank Dr Stephen Hursting (University of North Carolina) for the gift of cell preparations from Mmtv-Wnt1 tumors on a C57BL6 background. We thank Drs Evan Simpson (Monash University, Clayton, Victoria, Australia) and Kristy Brown (Monash University, Clayton, Victoria, Australia) for providing the LKB1-Luc promoter construct. The authors also thank Sneha Shivkumar (a Senior at the University of California, Irvine) and Ramya Swami (a Junior at the University of California, San Diego) for their assistance with the in vivo mouse experiments and GPCR data. We also thank the Breast Cancer Connection for their support.

\section{References}

Ahn J, Schatzkin A, Lacey JV Jr, Albanes D, Ballard-Barbash R, Adams KF, Kipnis V, Mouw T, Hollenbeck AR \& Leitzmann MF 2007 Adiposity, adult weight change, and postmenopausal breast cancer risk. Archives of Internal Medicine 167 2091-2102. (doi:10.1001/ archinte.167.19.2091)

Allott EH \& Hursting SD 2015 Obesity and cancer: mechanistic insights from transdisciplinary studies. Endocrine-Related Cancer 22 R365-R386. (doi:10.1530/ERC-15-0400)

Berstein LM, Kovalevskij AY, Poroshina TE, Kotov AV, Kovalenko IG, Tsyrlina EV, Leenman EE, Revskoy SY, Semiglazov VF \& Pozharisski KM 2007 Signs of proinflammatory/genotoxic switch (adipogenotoxicosis) in mammary fat of breast cancer patients: role of menopausal status, estrogens and hyperglycemia. International Journal of Cancer 121 514-519. (doi:10.1002/ijc.22552)

Boonchaya-anant P, Holick MF \& Apovian CM 2014 Serum 25-hydroxyvitamin D levels and metabolic health status in extremely obese individuals. Obesity 22 2539-2543. (doi:10.1002/oby.20877)

Bradford MM 1976 A rapid and sensitive method for the quantitation of microgram quantities of protein utilizing the principle of protein dye binding. Analytical Biochemistry 72 248-254. (doi:10.1016/00032697(76)90527-3)

Brown KA \& Simpson ER 2010 Obesity and breast cancer: progress to understanding the relationship. Cancer Research 70 4-7. (doi:10.1158/0008-5472.CAN-09-2257)

Brown KA, McInnes KJ, Hunger NI, Oakhill JS, Steinberg GR \& Simpson ER 2009 Subcellular localization of cyclic AMP-responsive element binding protein-regulated transcription coactivator 2 provides a link between obesity and breast cancer in postmenopausal women. Cancer Research 69 5392-5399. (doi:10.1158/0008-5472. CAN-09-0108)

Brown KA, Hunger NI, Docanto M \& Simpson ER 2010 Metformin inhibits aromatase expression in human breast adipose stromal cells via stimulation of AMP-activated protein kinase. Breast Cancer Research and Treatment 123 591-596. (doi:10.1007/s10549-0100834-y)

Bulun SE, Price TM, Aitken J, Mahendroo MS \& Simpson ER 1993 A link between breast cancer and local estrogen biosynthesis suggested by quantification of breast adipose tissue aromatase cytochrome P450 transcripts using competitive polymerase chain reaction after reverse transcription. Journal of Clinical Endocrinology \& Metabolism 77 $1622-1628$
Calle C, Maestro B \& Garcia-Arencibia M 2008 Genomic actions of 1,25-dihydroxyvitamin D3 on insulin receptor gene expression, insulin receptor number and insulin activity in the kidney, liver and adipose tissue of streptozotocin-induced diabetic rats. BMC Molecular Biology 9 65. (doi:10.1186/1471-2199-9-65)

Deeb KK, Trump DL \& Johnson CS 2007 Vitamin D signalling pathways in cancer: potential for anticancer therapeutics. Nature Reviews Cancer 7 684-700. (doi:10.1038/nrc2196)

Feldman D, Krishnan AV, Swami S, Giovannucci E \& Feldman BJ 2014 The role of vitamin $\mathrm{D}$ in reducing cancer risk and progression. Nature Reviews Cancer 14 342-357. (doi:10.1038/nrc3691)

Gilbert CA \& Slingerland JM 2013 Cytokines, obesity, and cancer: new insights on mechanisms linking obesity to cancer risk and progression. Annual Review of Medicine 64 45-57. (doi:10.1146/ annurev-med-121211-091527)

Grossmann ME, Ray A, Nkhata KJ, Malakhov DA, Rogozina OP, Dogan S \& Cleary MP 2010 Obesity and breast cancer: status of leptin and adiponectin in pathological processes. Cancer and Metastasis Reviews 29 641-653. (doi:10.1007/s10555-010-9252-1)

Hollis BW, Kamerud JQ, Selvaag SR, Lorenz JD \& Napoli JL 1993 Determination of vitamin D status by radioimmunoassay with an 125I-labeled tracer. Clinical Chemistry 39 529-533.

Hollis BW, Kamerud JQ, Kurkowski A, Beaulieu J \& Napoli JL 1996 Quantification of circulating 1,25-dihydroxyvitamin $\mathrm{D}$ by radioimmunoassay with 125I-labeled tracer. Clinical Chemistry $\mathbf{4 2}$ 586-592.

Howe LR, Subbaramaiah K, Hudis CA \& Dannenberg AJ 2013 Molecular pathways: adipose inflammation as a mediator of obesity-associated cancer. Clinical Cancer Research 19 6074-6083. (doi:10.1158/10780432.CCR-12-2603)

Hursting SD \& Berger NA 2010 Energy balance, host-related factors, and cancer progression. Journal of Clinical Oncology $\mathbf{2 8}$ 4058-4065. (doi:10.1200/JCO.2010.27.9935)

Iyengar NM, Hudis CA \& Dannenberg AJ 2015 Obesity and cancer: local and systemic mechanisms. Annual Review of Medicine $\mathbf{6 6}$ 297-309. (doi:10.1146/annurev-med-050913-022228)

Krishnan AV \& Feldman D 2011 Mechanisms of the anti-cancer and anti-inflammatory actions of vitamin D. Annual Review of Pharmacology and Toxicology 51 311-336. (doi:10.1146/annurevpharmtox-010510-100611)

Krishnan AV, Swami S, Peng L, Wang J, Moreno J \& Feldman D 2010 Tissue-selective regulation of aromatase expression by calcitriol: implications for breast cancer therapy. Endocrinology 151 32-42. (doi:10.1210/en.2009-0855)

Krishnan AV, Swami S \& Feldman D 2012 The potential therapeutic benefits of vitamin $\mathrm{D}$ in the treatment of estrogen receptor positive breast cancer. Steroids 77 1107-1112. (doi:10.1016/j.steroids.2012.06.005)

Liel Y, Ulmer E, Shary J, Hollis BW \& Bell NH 1988 Low circulating vitamin D in obesity. Calcified Tissue International 43 199-201. (doi:10.1007/BF02555135)

Luo Z, Zang M \& Guo W 2010 AMPK as a metabolic tumor suppressor: control of metabolism and cell growth. Future Oncology 6 457-470. (doi:10.2217/fon.09.174)

Maccio A, Madeddu C \& Mantovani G 2009 Adipose tissue as target organ in the treatment of hormone-dependent breast cancer: new therapeutic perspectives. Obesity Reviews 10 660-670. (doi:10.1111/j.1467-789X.2009.00592.x)

Matthews DR, Hosker JP, Rudenski AS, Naylor BA, Treacher DF \& Turner RC 1985 Homeostasis model assessment: insulin resistance and beta-cell function from fasting plasma glucose and insulin concentrations in man. Diabetologia 28 412-419. (doi:10.1007/ BF00280883)

McDaniel RE, Maximov PY \& Jordan VC 2013 Estrogen-mediated mechanisms to control the growth and apoptosis of breast cancer cells: a translational research success story. Vitamins and Hormones 93 1-49. (doi:10.1016/B978-0-12-416673-8.00007-1) 
Mitri J \& Pittas AG 2014 Vitamin D and diabetes. Endocrinology and Metabolism Clinics of North America 43 205-232. (doi:10.1016/ j.ecl.2013.09.010)

Moreno J, Krishnan AV, Swami S, Nonn L, Peehl DM \& Feldman D 2005 Regulation of prostaglandin metabolism by calcitriol attenuates growth stimulation in prostate cancer cells. Cancer Research $\mathbf{6 5}$ 7917-7925.

Nunez NP, Perkins SN, Smith NC, Berrigan D, Berendes DM, Varticovski L, Barrett JC \& Hursting SD 2008 Obesity accelerates mouse mammary tumor growth in the absence of ovarian hormones. Nutrition and Cancer 60 534-541. (doi:10.1080/01635580801966195)

Ouchi N, Parker JL, Lugus JJ \& Walsh K 2011 Adipokines in inflammation and metabolic disease. Nature Reviews Immunology $\mathbf{1 1}$ 85-97. (doi:10.1038/nri2921)

Rossdeutscher L, Li J, Luco AL, Fadhil I, Ochietti B, Camirand A, Huang DC, Reinhardt TA, Muller W \& Kremer R 2015 Chemoprevention activity of 25-hydroxyvitamin D in the MMTVPyMT mouse model of breast cancer. Cancer Prevention Research 8 120-128. (doi:10.1158/1940-6207.CAPR-14-0110)

Shui I \& Giovannucci E 2014 Vitamin D status and cancer incidence and mortality. Advances in Experimental Medicine and Biology $\mathbf{8 1 0}$ 33-51.

Simboli-Campbell M, Narvaez CJ, van Weelden K, Tenniswood M \& Welsh J 1997 Comparative effects of 1,25(OH)2D3 and EB1089 on cell cycle kinetics and apoptosis in MCF-7 breast cancer cells. Breast Cancer Research and Treatment 42 31-41. (doi:10.1023/A:1005772432465)

Simpson ER \& Brown KA 2013a Minireview: obesity and breast cancer: a tale of inflammation and dysregulated metabolism. Molecular Endocrinology 27 715-725. (doi:10.1210/me.2013-1011)

Simpson ER \& Brown KA 2013b Obesity and breast cancer: role of inflammation and aromatase. Journal of Molecular Endocrinology 51 T51-59. (doi:10.1530/JME-13-0217)

Simpson ER, Clyne C, Rubin G, Boon WC, Robertson K, Britt K, Speed C \& Jones M 2002 Aromatase - a brief overview. Annual Review of Physiology 64 93-127. (doi:10.1146/annurev.physiol. $64.081601 .142703)$

So JY \& Suh N 2015 Targeting cancer stem cells in solid tumors by vitamin D. Journal of Steroid Biochemistry and Molecular Biology 148 79-85. (doi:10.1016/j.jsbmb.2014.10.007)

Strong AL, Ohlstein JF, Biagas BA, Rhodes LV, Pei DT, Tucker HA, Llamas C, Bowles AC, Dutreil MF, Zhang S et al. 2015 Leptin produced by obese adipose stromal/stem cells enhances proliferation and metastasis of estrogen receptor positive breast cancers. Breast Cancer Research 17 112. (doi:10.1186/s13058-015-0622-z)

Swami S, Krishnan AV \& Feldman D 2000 1alpha,25-Dihydroxyvitamin D3 down-regulates estrogen receptor abundance and suppresses estrogen actions in MCF-7 human breast cancer cells. Clinical Cancer Research 6 3371-3379.

Swami S, Krishnan AV, Wang JY, Jensen K, Peng L, Albertelli MA \& Feldman D 2011 Inhibitory effects of calcitriol on the growth of MCF-7 breast cancer xenografts in nude mice: selective modulation of aromatase expression in vivo. Hormones and Cancer 2 190-202. (doi:10.1007/s12672-011-0073-7)

Swami S, Krishnan AV, Wang JY, Jensen K, Horst R, Albertelli MA \& Feldman D 2012 Dietary vitamin D(3) and 1,25-dihydroxyvitamin $\mathrm{D}$ (3) (calcitriol) exhibit equivalent anticancer activity in mouse xenograft models of breast and prostate cancer. Endocrinology 153 2576-2587. (doi:10.1210/en.2011-1600)

Swami S, Krishnan AV, Peng L, Lundqvist J \& Feldman D 2013 Transrepression of the estrogen receptor promoter by calcitriol in human breast cancer cells via two negative vitamin D response elements. Endocrine-Related Cancer 20 565-577. (doi:10.1530/ ERC-12-0281)

Wang YC, McPherson K, Marsh T, Gortmaker SL \& Brown M 2011 Health and economic burden of the projected obesity trends in the USA and the UK. Lancet 378 815-825. (doi:10.1016/S01406736(11)60814-3)

Wang X, Simpson ER \& Brown KA 2015 Aromatase overexpression in dysfunctional adipose tissue links obesity to postmenopausal breast cancer. Journal of Steroid Biochemistry and Molecular Biology 153 35-44. (doi:10.1016/j.jsbmb.2015.07.008)

Welsh J 2012 Cellular and molecular effects of vitamin D on carcinogenesis. Archives of Biochemistry and Biophysics 523 107-114. (doi:10.1016/j.abb.2011.10.019)

Yue W, Wang JP, Li Y, Bocchinfuso WP, Korach KS, Devanesan PD, Rogan E, Cavalieri E \& Santen RJ 2005 Tamoxifen versus aromatase inhibitors for breast cancer prevention. Clinical Cancer Research 11 925s-930s.

Zhao XY, Boyle B, Krishnan AV, Navone NM, Peehl DM \& Feldman D 1999 Two mutations identified in the androgen receptor of the new human prostate cancer cell line MDA PCa 2a. Journal of Urology 162 2192-2199. (doi:10.1016/S00225347(05)68158-X)

Received in final form 21 January 2016

Accepted 27 January 2016

Accepted Preprint published online 27 January 2016
(C) 2016 Society for Endocrinology Printed in Great Britain
Published by Bioscientifica Ltd 